\title{
Immunoglobulin G4-related diseases in the head and neck: a systematic review
}

\author{
Graeme B. Mulholland ${ }^{*}$ id, Caroline C. Jeffery, Paras Satija and David W. J. Côté
}

\begin{abstract}
Background: Immunoglobulin G4 related disease (IgG4-RD) is a poorly understood chronic inflammatory disorder affecting the middle-aged and elderly that can present to the otolaryngologist. We aim to summarize the current literature regarding the manifestations and management of IgG4-RD in the head and neck.

Methods: Pubmed and EMBASE were searched using the term relevant search algorithm utilizing keywords such as: IgG4 related disease, head and neck, orbit, salivary glands, sialadenitis, Kuttner, angiocentric eosinophilic fibrosis, submandibular, lacrimal, thyroid, dacryoadenitis, nasal, sinus, and Mikulicz's. Reference lists were searched for identification of relevant studies.

Case reports, original research and review articles published in English from 1964 to 2014 whose major topic was IgG4-RD affecting the head and neck were included. Data regarding patient demographics, presentation, histopathology, management and treatment outcomes of IgG4-RD were extracted. Level of evidence was also assessed and data were pooled where possible. Three independent reviewers screened eligible studies; extracted relevant data and discrepancies were resolved by consensus, where applicable. Descriptive and comparative statistics were performed.
\end{abstract}

Results: Fourty-three articles met our inclusion criteria. lgG4-RD most often presents as a mass lesion in the head and neck region. Common diagnostic features include: 1) elevated serum lgG4 level, 2) marked infiltration of exocrine glands by IgG4-positive plasma cells with fibrosis, and 3) marked improvement with corticosteroid therapy and additional immunosuppressive therapy in corticosteroid refractory cases. Early diagnosis and involvement of rheumatology is important in management.

Conclusions: IgG4-RD is a challenging non-surgical disease that has multiple manifestations in the head and neck. It must be distinguished from various mimics including malignancy, systemic diseases, and infectious. Otolaryngology-Head and Neck surgeons should be aware of this condition and its management.

Keywords: IgG4-RD, Head and neck, Systematic review, Salivary glands, Lacrimal glands, Lymphandenopathy

\section{Introduction}

Immunoglobulin G4 - related disease (IgG4-RD) is a newly described fibroinflammatory condition that often presents as a tumefactive lesion that can affect nearly every organ system. IgG4-RD was first recognized after a connection between elevated serum IgG4 levels and inflammatory mass lesions in the pancreas causing autoimmune pancreatitis was made by Hamano et al. in 2001 [1]. An initial consensus statement regarding diagnosis of IgG4-RD was developed by Deshpande et al. at

\footnotetext{
* Correspondence: graemem@ualberta.ca

Division of Otolaryngology-Head and Neck Surgery, 1E4 Walter MacKenzie Centre, University of Alberta, 8440112 Street, Edmonton, AB T6G 2B7, Canada
}

(c) 2015 Mulholland et al. This is an Open Access article distributed under the terms of the Creative Commons Attribution License (http://creativecommons.org/licenses/by/4.0) which permits unrestricted use, distribution, and reproduction in any medium, provided the original work is properly credited. The Creative Commons Public Domain Dedication waiver (http:// creativecommons.org/publicdomain/zero/1.0/) applies to the data made available in this article, unless otherwise stated. October of 2011 [2]. After the pancreas, the head and neck region is second most common site for presentation of IgG4-RD. More, a number of historically perplexing pseudotumor disorders have been attributed to IgG4-RD; these include Mikulicz's disease, Küttner's tumor and Reidel's thyroiditis [3].

The exact etiology of IgG4-RD is unknown and no known role of the IgG4 molecule itself has been identified. It is postulated that the inflammatory and fibrotic processes that drives IgG4-RD are propagated by a combination of Th2 cells and regulatory T cells (Treg cells) [4]. This is contrary to most autoimmune disorders where 
polarized T helper 1 (Th1) and/or Th17 subsets are responsible for the inflammatory process [5]. Histologically, the hallmark findings for IgG4-RD include lymphoplasmacytic infiltration, storiform fibrosis, obliterative phlebitis, and mild to moderate tissue eosinophilia [6]. However, the exact histological findings vary greatly depending on the tissue affected and clinical presentation. Currently, the histologic diagnosis of IgG4-RD is based primarily on IgG4 positive to IgG containing cell ratio and the number of IgG4 positive cells per high powered field, a ratio of IgG4 to IgG that is higher than $50 \%$ and 30 IgG4positive cells per high-power field is considered to be highly suggestive of IgG4-RD [6].
Currently, the literature proposes that IgG4-RD could be both over and under recognised [7]. This study aims to examine the various presentations of IgG4-RD in the head and neck, and present the management and outcomes reported in the literature.

\section{Material and methods}

This systematic review was performed using the following search strategy and study selection criteria.

\section{Literature search strategy}

The databases PubMed (1966-December 2014) and Embase (1988-December 2014) were searched using an

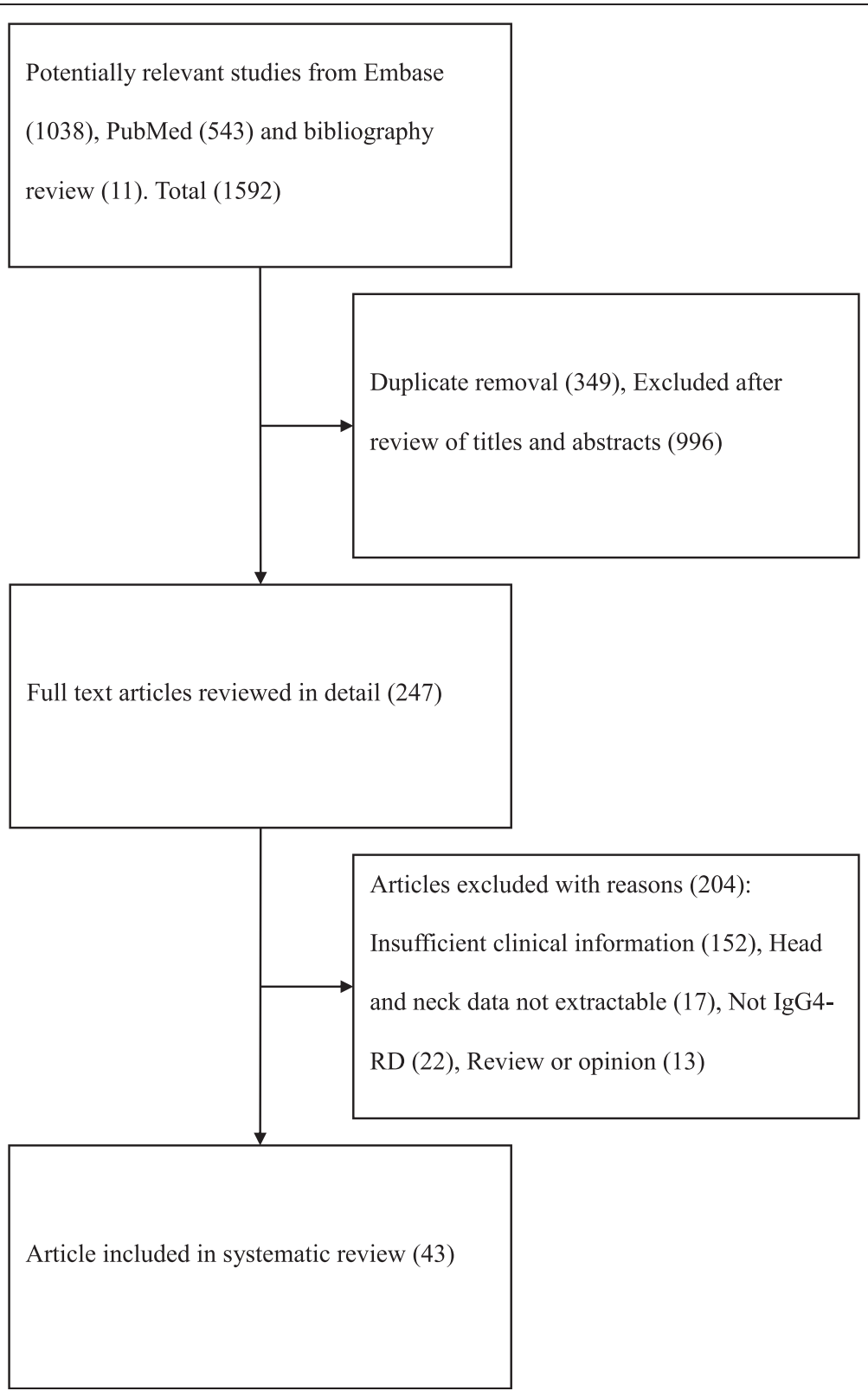

Fig. 1 Flow chart of studies obtained through literature search, eligible and excluded (Uploaded separately as per submission instructions) 
algorithm designed from an extensive list of relevant search terms (see Appendix A for Pubmed and Embase search algorithms).

We included all original studies, case reports, case series, and reviews. Relevant articles and abstracts were selected and reviewed and the reference lists from these sources and recent review articles were also reviewed for additional publications.

\section{Study selection}

Three independent reviewers screened the identified articles (GBM, CCJ and PS). Relevant articles were obtained and reviewed in full. Discrepancies were resolved by consensus amongst the reviewers. The inclusion criteria comprised of all original clinical studies, case series and case reports of histologically confirmed IgG4-RD in the head and neck. Histologic diagnosis of IgG4-RD required identification of $>10$ IgG4 positive plasma cells per high powered field, IgG4 + plasma cell to IgG containing cell ratio $40 \%$ or greater, and characteristic finding of fibrosis, sclerosis and phlebitis. Articles were excluded on the basis of biopsy information not being from a head and neck site, insufficient histologic information, inability to extract head and neck specific information and narrative review and expert opinions.

\section{Data extraction}

The information gathered for each study included study design, country of publication and number of patients. Where possible, patient-specific data was extracted, including age at presentation, duration and nature of symptoms. Specifically, we collected data regarding head and neck manifestations, laboratory and histologic findings as well as specific treatments and outcome information.

\section{Statistical analysis}

Basic statistical analysis, including descriptive statistics was performed using Excel (Version 19.0, Microsoft ${ }^{\circ}$ ).

\section{Results}

We initially identified 1592 articles through a combination of literature search and citation review. After reviewing abstracts, 247 articles of interest were identified. Three authors independently reviewed the articles and 43 articles met inclusion criteria (Fig. 1). Of the 43 articles, 21 case reports and 5 large case series (greater than 15 patients) were included (Table 1). A large

Table 1 Country of origin and characteristics of included articles

N (Articles) $\quad \% \quad N$ (Individual Cases) $\quad \%$

\begin{tabular}{|c|c|c|c|c|c|c|}
\hline \multirow[t]{4}{*}{ Total number of studies } & & & 43 & & 484 & \\
\hline & Case Reports & & 21 & 48.8 & 21 & 4.3 \\
\hline & Small Case Series & & 17 & 39.5 & 107 & 22.1 \\
\hline & Large Case Series & & 5 & 11.6 & 356 & 73.6 \\
\hline \multirow[t]{18}{*}{ Country of Origin } & North America & & 10 & 23.3 & 27 & 5.6 \\
\hline & & Canada & 1 & 2.3 & 1 & 0.2 \\
\hline & & USA & 9 & 20.9 & 26 & 5.4 \\
\hline & Asia & & 22 & 51.2 & 429 & 88.6 \\
\hline & & Japan & 18 & 41.9 & 419 & 86.6 \\
\hline & & Hong Kong & 2 & 4.7 & 8 & 1.7 \\
\hline & & Taiwan & 1 & 2.3 & 1 & 0.2 \\
\hline & & Singapore & 1 & 2.3 & 1 & 0.2 \\
\hline & Oceania & & 6 & 14.0 & 7 & 1.4 \\
\hline & & Australia & 5 & 11.6 & 6 & 1.2 \\
\hline & & New Zealand & 1 & 2.3 & 1 & 0.2 \\
\hline & Europe & & 4 & 9.3 & 20 & 4.1 \\
\hline & & United Kingdom & 1 & 2.3 & 1 & 0.2 \\
\hline & & Netherlands & 1 & 2.3 & 12 & 2.5 \\
\hline & & Czech Republic & 1 & 2.3 & 6 & 1.2 \\
\hline & & Switzerland & 1 & 2.3 & 1 & 0.2 \\
\hline & South America & & 1 & 2.3 & 1 & 0.2 \\
\hline & & Brazil & 1 & 2.3 & 1 & 0.2 \\
\hline
\end{tabular}


Table 2 Basic patient demographics

\begin{tabular}{ll}
\hline Total number of Patients & 484 \\
Average Age (years) & 60.4 \\
Percent Males & $47.5 \%$ \\
\hline
\end{tabular}

proportion of articles were from Japan (41.9\%), contributing $86.6 \%$ of the total individual cases (Table 1).

Four hundred and eighty-four patients were identified with an average patient age of 60.4 years (Table 2). Table 3 shows the proportion of patients presenting by various sites in the head and neck. Cervical lymphadenopathy was document in 22 cases. Many of the patients also had involvement of other organ systems at the time of presentation, including 56 patients with lymphadenopathy outside of the head and neck (see Table 3). All patients had tissue biopsy from head and neck sites confirming the diagnosis of IgG4-RD. Confirmatory laboratory investigations was included where documented. The laboratory and histologic findings of patients indentified in the literature are summarized in Table 4.

Treatment information was available for $26.7 \%$ of patients. Patients were treated with surgical excision, radiotherapy, corticosteroids with or without adjunct medical

Table 3 Systemic and head and neck manifestations

\begin{tabular}{|c|c|c|c|c|}
\hline $\begin{array}{l}\text { Head \& Neck } \\
\text { Manifestations }\end{array}$ & Site & Subsite & $\mathrm{n}$ & $\%$ \\
\hline & Total presentations & & 730 & \\
\hline & Orbit & & 384 & 52.6 \\
\hline & & Lacrimal Gland & 136 & 18.6 \\
\hline & & Extra Ocular Muscles & 9 & 1.2 \\
\hline & & Optic Nerve & 5 & 0.7 \\
\hline & Salivary Glands & & 162 & 22.2 \\
\hline & & Submandibular Gland & 107 & 14.7 \\
\hline & & Parotid Gland & 29 & 4.0 \\
\hline & & Sublingual Gland & 1 & 0.1 \\
\hline & & Minor Salivary Gland & 1 & 0.1 \\
\hline & Thyroid & & 31 & 4.2 \\
\hline & Facial Skin & & 6 & 0.8 \\
\hline & Trigeminal Nerve & & 1 & 0.1 \\
\hline & $\begin{array}{l}\text { Cervical } \\
\text { Lymphadenopathy }\end{array}$ & & 22 & 3.0 \\
\hline \multirow{3}{*}{$\begin{array}{l}\text { Non Head } \\
\text { \& Neck } \\
\text { Manifestations }\end{array}$} & Site & & $n$ & $\%$ \\
\hline & $\begin{array}{l}\text { Other Organ } \\
\text { Involvement }\end{array}$ & & 68 & 9.3 \\
\hline & $\begin{array}{l}\text { Mediastinal/Pelvic } \\
\text { Lymphadenopathy }\end{array}$ & & 56 & 7.7 \\
\hline
\end{tabular}

Table 4 Laboratory and histologic findings

\begin{tabular}{lc}
\hline & Mean Values \\
\hline Serum lgG4 (mg/dL) & 702.9 \\
Serum lgG (mg/dL) & 2445.0 \\
lgG4 + ve Plasma Cells / HPF & 69.8 \\
lgG4 + ve Cells / lgG Containing Cells & $48.0 \%$ \\
\hline
\end{tabular}

treatment, or some combination of treatment modalities. The distribution of patients in terms of treatment(s) received and their outcomes are summarized in Table 5 . Treatment outcomes were known in 99 patients. Of these, full remission was seen in $90.0 \%$ in response to medical treatment. Corticosteroids treatment alone was effective for 67 patients (67.7 \%) in achieving full remission.

\section{Discussion}

This is the first systematic review of IgG4-RD presentation in the head and neck. Our study demonstrates a strong propensity for IgG4-RD to present in the head and neck region. We included 43 articles containing 484 patients. The most common site of presentation was the orbit, followed by the submandibular gland - with many patients having presentations in multiple head and neck and distant sites. Treatment information was also collected, showing that majority of patients receiving corticosteroids responded very well to treatment.

The vast majority of the included cases were from Asia (429 of 484 or $88.6 \%$ ) and more specifically Japan (419 of 484 or $86.6 \%$ ). Indeed, much of the literature on IgG4-RD originates from Japan [8]. This poses the question of whether IgG4-RD more prevalent in the Japanese population or simply better recognized? While IgG4-RD was first recognized in Japan, it is increasingly recognized throughout the rest of the world [7]. While cases have been reported on every continent and in most ethnic groups, reports from countries outside of Asia comprise smaller case series. This highlights the emerging status of IgG4-RD in the literature and likely an increase in reporting in the future.

While systemic presentations of IgG4-RD favor males over females with a reported ratio of 2.8-3.5:1, our study demonstrates an almost 1 to 1 ratio of head and neck manifestations $[6,9,10]$. Orbital involvement was most common subsite in the head and neck and the majority of the orbital presentations (219 cases) came from a single study [11]. Common orbital manifestations included periorbital swelling, eyelid swelling, and proptosis. Salivary gland and lacrimal gland involvement were very common and included submandibular, parotid gland, and lacrimal gland enlargement, infiltration, and formation of pseudotumours. Lymphadenopathy was a 
Table 5 Treatment and progress

\begin{tabular}{|c|c|c|c|}
\hline Treatments Received by Patients $(N=129)$ & & $n$ & $\%$ \\
\hline Surgical Management Alone & & 15 & 11.6 \\
\hline Combined Surgical and Medical Management & & 4 & 3.1 \\
\hline \multirow[t]{4}{*}{ Medical Management Alone } & & 107 & 82.9 \\
\hline & Treatment with Corticosteroids ${ }^{\mathrm{a}}$ Alone & 84 & 65.1 \\
\hline & $\begin{array}{l}\text { Treatment with Corticosteroids and One Additional } \\
\text { Immunosuppressive Agent }{ }^{b}\end{array}$ & 16 & 12.4 \\
\hline & $\begin{array}{l}\text { Treatment with Corticosteroids and Multiple Additional } \\
\text { Immunosuppressive Agents }\end{array}$ & 10 & 7.8 \\
\hline Treatment Outcomes $(N=99)$ & & $n$ & $\%$ \\
\hline Full Remission with Medical Treatment & & 89 & 90.0 \\
\hline \multirow[t]{2}{*}{ Full Remission with Corticosteroids Alone } & & 67 & 67.7 \\
\hline & $\begin{array}{l}\text { Intolerance, Relapse with Taper, or Treatment Failure with } \\
\text { Corticosteroids as First Line }\end{array}$ & 32 & 32.3 \\
\hline $\begin{array}{l}\text { Full Remission with Addition of Single Immunosuppressive Agent to } \\
\text { Corticosteroids }\end{array}$ & & 14 & 14.1 \\
\hline $\begin{array}{l}\text { Full Remission with Addition of Multiple Immunosuppressive Agents } \\
\text { to Corticosteroids }\end{array}$ & & 8 & 8.1 \\
\hline Remission Not Achieved & & 9 & 9.1 \\
\hline
\end{tabular}

${ }^{a}$ Corticosteroids included: prednisolone, methylprednisone and triamcinolone injections

${ }^{b}$ Additional immunosuppressive agents included: rituximab, methotrexate, azathioprine, mycophenolate mofetil, tamoxifen, 6-mercaptopurine, chlorambucil, cyclosporine and cyclopohosphamide

particularly common presentation in the head and neck. This was often associated with lymphadenopathy elsewhere including the mediastinum and retroperitoneum. More rare forms of head and neck involvement included the thyroid gland in the form of Riedel's Thyroiditis as well as sinonasal and airway manifestations.

Few patients in our series received surgical excision alone. The majority cases received some form of medical management comprising of high-dose corticosteroids. Patients had excellent response to medical therapy alone with full remission rate of $90 \%$. A consensus statement from 17 referral centres in Japan developed a treatment regime of $0.6 \mathrm{mg} / \mathrm{Kg}$ prednisolone for 2 to 4 weeks with a taper over 3 to 6 months and a low daily dose for 3 years. Importantly, this regime was developed for treatment of autoimmune pancreatitis, where consequences of not treating are associated with significant morbidity and mortality [12]. However, other authors advocate watchful waiting with observation over a number of years as an acceptable treatment approach [13]. Based on our results, surgery remains most useful for obtaining histologic diagnosis.

Strict selection criteria was used in article selection. Histologic diagnosis was based on IgG4 + ve cells/ HPF and the IgG4 + ve/IgG ratio. This is considered the most rigorous definition of IgG4-RD [4, 6]. However, since biopsy from the head and neck was one of the criteria, there are likely many studies of IgG4-RD in the head and neck that were excluded as biopsies were obtained from other tissues. Unfortunately, there is a paucity of high quality publications on this topic. The majority of the information available exists in the form of case reports and small case series, which comprise of low level of evidence. There are also inconsistencies in reporting key information. Many studies were excluded due to insufficient information (152 or $74.5 \%$ ) or a lack of basic histologic information; articles lacking IgG4+ cell/HPF or the IgG4+/IgG ratio -items critical to confirming the presence of IgG4-RD-- were excluded.

\section{Conclusions}

Due to the numerous potential manifestations of IgG4-RD in the head and neck, it is crucial for otolaryngologists to be aware of this condition. A high index of suspicious is required particularly in the setting of patients who present with recurrent salivary and lacrimal gland swelling, lymphadenopathy, along with fibroinflammatory systemic involvement. This disease process remains under recognized and poorly understood. Future studies are necessary to better understand the pathophysiology and natural history of this disease.

\section{Appendix A: search strategy}

Ovid: Embase search:

1. exp salivary gland/

2. mouth disease/ or lip disease/ or exp mouth tumor/ or exp palate disease/ or exp pharynx disease/ or 
exp salivary gland disease/ or exp tongue disease/ or xerostomia/

3. head/ or exp "face, nose and sinuses"/ or exp skull/

4. "head and neck disease"/ or exp "head and neck tumor"।

5. neck/

6. exp lacrimal apparatus/

7. exp lacrimal gland disease/

8. exp ear nose throat disease/

9. angiocentric eosinophilic fibrosis.mp.

10. (Facial or eyelid* or mouth or oral or gingival or lip or lips or palate or palatal or tonsil* or sinuses or sinus cavit* or salivary gland* or tongue or otorhinolaryngologic or ear or ears or larynx or laryngeal or nose or noses or paranasal or pharyngeal or parathyroid or thyroid or tracheal or sialadenitis or kuttner or submandibular or lacrimal or thyroid or dacryoadenitis or orbit or mikulicz*).ti,ab.

11. or $/ 1-10$

12. (immunoglobulin g4 or igg4).mp.

13. 11 and 12

14. limit 13 to english language

15. limit 14 to exclude medline journals

16. 14 not 15

17. limit 16 to (conference abstract or conference paper or conference proceeding or "conference review")

18. 14 not 17

19. limit 18 to embase

Ovid: Pubmed search:

1. exp Salivary Gland Diseases/

2. exp Head/

3. Neck/

4. exp Lacrimal Apparatus Diseases/ or exp Lacrimal Apparatus/ or exp Lacrimal Duct Obstruction/

5. angiocentric eosinophilic fibrosis.mp.

6. nose diseases/ or granuloma, lethal midline/ or nasal obstruction/ or exp nose neoplasms/ or exp paranasal sinus diseases/

7. orbital diseases/ or exp exophthalmos/ or orbital pseudotumor/

8. exp Frontal Sinus/ or exp Sphenoid Sinus/ or exp Maxillary Sinus/ or exp Pyriform Sinus/ or exp Ethmoid Sinus/

9. (Facial or eyelid* or mouth or oral or gingival or lip or lips or palate or palatal or tonsil" or sinuses or sinus cavit* or salivary gland* or tongue or otorhinolaryngologic or ear or ears or larynx or laryngeal or nose or noses or paranasal or pharyngeal or parathyroid or thyroid or tracheal or sialadenitis or kuttner or submandibular or lacrimal or thyroid or dacryoadenitis or orbit* or mikulicz*).mp.

10. (immunoglobulin g4 or igg4).mp.

11. or/1-9

12. 10 and 11

13. limit 12 to english language

14. remove duplicates from 13

Competing interests

The authors declare that they have no competing interests.

\section{Authors' contributions}

GBM was involved in study design, carried out literature search, reviewed all articles, collected data, performed statistical analysis and drafted the manuscript. CCJ contributed to conception of idea for project and study design, reviewed articles critically, collected data and writing the manuscript. PS critically reviewed articles, collected data and assisted in with writing the manuscript. DWJC conceived of the study, and participated in its design and coordination and helped to draft the manuscript. All authors read and approved the final manuscript.

\section{Acknowledgement}

The authors would like to thank Dr. Hamdy El-Hakim MB, ChB, Associate Clinical Professor in the Department of Surgery and Research Director for the Division of Otolaryngology at the University of Alberta for direction in study design. As well as Mr. Dale Storie MA, MILS, Liaison librarian to the School of Public Health and Faculty of Medicine and Dentistry, University of Alberta for his kind and thorough assistance in developing search algorithm.

Received: 17 January 2015 Accepted: 5 May 2015

Published online: 20 June 2015

\section{References}

1. Hamano H, Kawa S, Horiuchi A. High serum lgG4 concentrations in patients with sclerosing pancreatitis. N Engl J Med. 2001:344(10):732-8.

2. Deshpande V, Zen Y, Chan JK. Consensus statement on the pathology of IgG4-related disease. Mod Pathol. 2012;25(9):1181-92.

3. Umehara H, Okazaki K, Masaki Y. A novel clinical entity, lgG4-related disease (IgG4RD): General concept and details. Mod Rheumatol. 2012;22(1):1-14.

4. Zen Y, Nakanuma Y. Pathogenesis of IgG4-related disease. Curr Opin Rheumatol. 2011;23(1):114-8.

5. Stromnes IM, Cerretti LM, Liggitt D, Harris RA, Goverman JM. Differential regulation of central nervous system autoimmunity by $T(H) 1$ and $T(H) 17$ cells. Nat Med. 2008:14(3):337-42.

6. Stone JH, Zen Y, Deshpande V. IgG4-related disease. N Engl J Med. 2012;366(6):539-51.

7. Cheuk W, Chan JK. Lymphadenopathy of IgG4-related disease: an underdiagnosed and overdiagnosed entity. Semin Diagn Pathol. 2012;29(4):226-34.

8. Brito-Zeron P, Ramos-Casals M, Bosch X, Stone JH. The clinical spectrum of IgG4-related disease. Autoimmun Rev. 2014;13(12):1203-10.

9. Mahajan VS, Mattoo H, Deshpande V, Pillai SS, Stone JH. IgG4-related disease. Annu Rev Pathol. 2014:9:315-47.

10. Kanno A, Nishimori I, Masamune A. Nationwide epidemiological survey of autoimmune pancreatitis in japan. Pancreas. 2012:41(6):835-9.

11. Japanese study group of IgG4-related ophthalmic disease. A prevalence study of IgG4-related ophthalmic disease in japan. Jpn J Ophthalmol. 2013;57(6):573-9.

12. Kamisawa T, Shimosegawa T, Okazaki K. Standard steroid treatment for autoimmune pancreatitis. Gut. 2009;58(11):1504-7.

13. Sato $Y$, Ohshima K, Ichimura K, et al. Ocular adnexal IgG4-related disease has uniform clinicopathology. Pathol Int. 2008;58(8):465-70.

\section{Further reading}

Abe T, Sato T, Tomaru Y, et al. Immunoglobulin G4-related sclerosing sialadenitis: Report of two cases and review of the literature. Oral Surg Oral Med Oral Pathol Oral Radiol Endod. 2009;108(4):544-50.

Aga M, Kondo S, Yamada K, et al. Warthin's tumor associated with IgG4-related disease. Auris Nasus Larynx. 2013;40(5):514-7. 
Andrew N, Kearney D, Sladden N, Goss A, Selva D. Immunoglobulin G4-related disease of the hard palate. J Oral Maxillofac Surg. 2014;72(4):717-23.

Bosco JJ, Suan D, Varikatt W, Lin MW. Extra-pancreatic manifestations of IgG4related systemic disease: A single-centre experience of treatment with combined immunosuppression. Intern Med J. 2013;43(4):417-23.

Caputo C, Bazargan A, McKelvie PA, Sutherland T, Su CS, Inder WJ. Hypophysitis due to lgG4-related disease responding to treatment with azathioprine: An alternative to corticosteroid therapy. Pituitary. 2014;17(3):251-6.

Chen TS, Figueira E, Lau OC, et al. Successful "medical" orbital decompression with adjunctive rituximab for severe visual loss in lgG4-related orbital inflammatory disease with orbital myositis. Ophthal Plast Reconstr Surg. 2014.

Cheuk W, Lee KC, Chong LY, Yuen ST, Chan JK. IgG4-related sclerosing disease: A potential new etiology of cutaneous pseudolymphoma. Am J Surg Pathol. 2009:33(11):1713-9.

Cheuk W, Yuen HK, Chan JK. Chronic sclerosing dacryoadenitis: Part of the spectrum of IgG4-related sclerosing disease? Am J Surg Pathol. 2007;31(4):643-5.

da Fonseca FL, Ramos Rde I, de Lima PP, Nogueira AB, Matayoshi S. Unilateral eyelid mass as an unusual presentation of ocular adnexal lgG4-related inflammation. Cornea. 2013;32(4):517-9.

Dahlgren M, Khosroshahi A, Nielsen GP, Deshpande V, Stone JH. Riedel's thyroiditis and multifocal fibrosclerosis are part of the lgG4-related systemic disease spectrum. Arthritis Care Res (Hoboken). 2010;62(9):1312-8.

Deshpande V, Khosroshahi A, Nielsen GP, Hamilos DL, Stone JH. Eosinophilic angiocentric fibrosis is a form of IgG4-related systemic disease. Am J Surg Pathol. 2011;35(5):701-6.

Geyer JT, Ferry JA, Harris NL, et al. Chronic sclerosing sialadenitis (kuttner tumor) is an IgG4-associated disease. Am J Surg Pathol. 2010;34(2):202-10.

Gill J, Angelo N, Yeong ML, Mclvor N. Salivary duct carcinoma arising in IgG4related autoimmune disease of the parotid gland. Hum Pathol. 2009;40(6):881-6.

Hagiya C, Tsuboi H, Yokosawa M, et al. Clinicopathological features of IgG4related disease complicated with orbital involvement. Mod Rheumatol. 2014;24(3):471-6

Higashiyama T, Nishida Y, Ugi S, Ishida M, Nishio Y, Ohji M. A case of extraocular muscle swelling due to lgG4-related sclerosing disease. Jpn J Ophthalmol. 2011;55(3):315-7.

Inaba H, Hayakawa T, Miyamoto W, et al. IgG4-related ocular adnexal disease mimicking thyroid-associated orbitopathy. Intern Med. 2013;52(22):2545-51.

Jalilian C, Prince HM, McCormack C, Lade S, Cheah CY. IgG4-related disease with cutaneous manifestations treated with rituximab: Case report and literature review. Australas J Dermatol. 2014;55(2):132-6.

Japanese study group of IgG4-related ophthalmic disease. A prevalence study of lgG4-related ophthalmic disease in japan. Jpn J Ophthalmol. 2013;57(6):573-9

Kase S, Suzuki Y, Shinohara T, Kase M. IgG4-related lacrimal sac diverticulitis. Orbit. 2014;33(3):217-9.

Katsura M, Morita A, Horiuchi H, Ohtomo K, Machida T. IgG4-related inflammatory pseudotumor of the trigeminal nerve: Another component of IgG4-related sclerosing disease? AJNR Am J Neuroradiol. 2011;32(8):E150-2.

Khan T, Halat SK, Al Hariri AB. Lacrimal gland sparing IgG4-related disease in the orbit. Ocul Immunol Inflamm. 2013;21(3):220-4.

Khosroshahi A, Carruthers MD, Deshpande V, Leb L, Reed Jl, Stone JH. Cutaneous immunoglobulin G4-related systemic disease. Am J Med. 2011;124(10):e7-8.

Khosroshahi A, Carruthers MN, Deshpande V, Unizony S, Bloch DB, Stone JH. Rituximab for the treatment of IgG4-related disease: Lessons from 10 consecutive patients. Medicine (Baltimore). 2012;91(1):57-66

Laco J, Ryska A, Celakovsky P, Dolezalova H, Mottl R, Tucek L. Chronic sclerosing sialadenitis as one of the immunoglobulin G4-related diseases: A clinicopathological study of six cases from central europe. Histopathology. 2011:58(7):1157-63

Lee LY, Chen TC, Kuo TT. Simultaneous occurrence of IgG4-related chronic sclerosing dacryoadenitis and chronic sclerosing sialadenitis associated with lymph node involvement and warthin's tumor. Int J Surg Pathol. 2011;19(3):369-72.

Li Y, Zhou G, Ozaki T, et al. Distinct histopathological features of hashimoto's thyroiditis with respect to lgG4-related disease. Mod Pathol. 2012;25(8):1086-97.

Matsuo T, Ichimura K, Sato Y, et al. Immunoglobulin G4 (lgG4)-positive or -negative ocular adnexal benign lymphoid lesions in relation to systemic involvement. J Clin Exp Hematop. 2010;50(2):129-42.
Mudhar HS, Bhatt R, Sandramouli S. Xanthogranulomatous variant of immunoglobulin G4 sclerosing disease presenting as ptosis, proptosis and eyelid skin plaques. Int Ophthalmol. 2011;31(3):245-8.

Origuchi T, Yano H, Nakamura H, Hirano A, Kawakami A. Three cases of IgG4related orbital inflammation presented as unilateral pseudotumor and review of the literature. Rheumatol Int. 2013;33(11):2931-6.

Paulus YM, Cockerham KP, Cockerham GC, Gratzinger D. IgG4-positive sclerosing orbital inflammation involving the conjunctiva: A case report. Ocul Immunol Inflamm. 2012;20(5):375-7.

Pusztaszeri M, Triponez F, Pache JC, Bongiovanni M. Riedel's thyroiditis with increased lgG4 plasma cells: Evidence for an underlying lgG4-related sclerosing disease? Thyroid. 2012;22(9):964-8.

Sato Y, Takeuchi M, Takata K, et al. Clinicopathologic analysis of IgG4-related skin disease. Mod Pathol. 2013;26(4):523-32.

Singh K, Rajan KD, Eberhart C. Orbital necrobiotic xanthogranuloma associated with systemic IgG4 disease. Ocul Immunol Inflamm. 2010;18(5):373-8.

Suzuki M, Nakamaru Y, Akazawa $\mathrm{S}$, et al. Nasal manifestations of immunoglobulin G4-related disease. Laryngoscope. 2013;123(4):829-34.

Takahashi H, Yamamoto M, Tabeya T, et al. The immunobiology and clinical characteristics of IgG4 related diseases. J Autoimmun. 2012;39(1-2):93-6.

Takahashi Y, Kitamura A, Kakizaki H. Bilateral optic nerve involvement in immunoglobulin G4-related ophthalmic disease. J Neuroophthalmol. 2014;34(1):16-9.

Takahira M, Ozawa Y, Kawano M, et al. Clinical aspects of IgG4-related orbital inflammation in a case series of ocular adnexal lymphoproliferative disorders. Int J Rheumatol. 2012;2012:635473.

Tay SH, Thamboo TP, Teng GG. A case of multi-system IGG4-related disease. Int J Rheum Dis. 2013;16(5):599-601.

Teichman JC, Wu AY, El-Shinnawy I, Harvey JT. A case of orbital involvement in IgG4-related disease. Orbit. 2012;31(5):327-9.

Verdijk RM, Heidari P, Verschooten R, van Daele PL, Simonsz HJ, Paridaens D. Raised numbers of lgG4-positive plasma cells are a common histopathological finding in orbital xanthogranulomatous disease. Orbit. 2014;33(1):17-22.

Wallace ZS, Khosroshahi A, Jakobiec FA, et al. IgG4-related systemic disease as a cause of "idiopathic" orbital inflammation, including orbital myositis, and trigeminal nerve involvement. Surv Ophthalmol. 2012;57(1):26-33.

Yamamoto $H_{1}$, Yamaguchi H, Aishima S, et al. Inflammatory myofibroblastic tumor versus IgG4-related sclerosing disease and inflammatory pseudotumor: A comparative clinicopathologic study. Am J Surg Pathol. 2009;33(9):1330-40.

Zen Y, Nakanuma Y. IgG4-related disease: a cross-sectional study of 114 cases. Am J Surg Pathol. 2010;34(12):1812-9.

\section{Submit your next manuscript to BioMed Central and take full advantage of:}

- Convenient online submission

- Thorough peer review

- No space constraints or color figure charges

- Immediate publication on acceptance

- Inclusion in PubMed, CAS, Scopus and Google Scholar

- Research which is freely available for redistribution 